\title{
A atuação do enfermeiro em comissão intra-hospitalar de doação de órgãos e tecidos
}

\author{
The role of nurses in the intra-hospitalar organ and tissue donation commission \\ El papel de la enfermera en la comisión intrahospitalaria de donación de órganos y tejidos
}

\author{
Fernando Dalmaso Tolfo'; Silviamar Camponogara"'; Maria José López Montesinos "II, \\ Carmem Lucia Colomé Beck ${ }^{\text {iv }}$; Suzinara Beatriz Soares de Limav; Gisele Loise Dias ${ }^{\text {VI }}$
}

\begin{abstract}
RESUMO
Objetivo: conhecer o papel do enfermeiro de comissão intra-hospitalar de doação de órgãos e tecidos para transplante. Método: estudo qualitativo, desenvolvido em cinco hospitais de uma região metropolitana do Sul do Brasil. Os dados foram coletados por entrevista semiestruturada com 12 enfermeiros e analisados de acordo com a análise de conteúdo temática. Resultados: Emergiram três categorias temáticas: o papel do enfermeiro na busca ativa, o enfermeiro e as questões burocráticas da comissão intra-hospitalar de doação de órgãos e tecidos e o enfermeiro e a família do potencial doador de órgãos. O enfermeiro é considerado um elo entre a equipe da comissão e os demais envolvidos no processo de doação e captação de órgãos. Conclusão: o enfermeiro está presente em todas as etapas do processo e tem papel importante na busca ativa, na gestão e observação atenta do cuidado de enfermagem ao potencial doador

Descritores: Enfermagem; papel do profissional de enfermagem; transplantes; obtenção de tecidos e órgãos.
\end{abstract}

\section{ABSTRACT}

Objective: to learn about the role of the nurse on the in-hospital commission on donation of organs and tissues for transplantation Method: in this qualitative study conducted in five hospitals in a metropolitan region of south Brazil, data were collected by semi structured interviews of 12 nurses, and treated using thematic content analysis. Results: three thematic categories emerged: the role of the nurse in active detection, the nurse and administrative procedures of the organ and tissue donation commission, and the nurse and the potential organ donor's family. The nurse is regarded as linking between the commission team and others involved in the organ donation and harvesting process. Conclusion: the nurse is present at all stages of the process, and also plays an important role in active detection, and in management and careful observation of nursing care for potential donors.

Descriptors: Nursing; nurse's role; transplants; tissue and organ procurement.

\section{RESUMEN}

Objetivo: conocer el papel de la enfermera de comisión intrahospitalaria de donación de órganos y tejidos para trasplante. Método: estudio cualitativo, desarrollado en cinco hospitales de una región metropolitana del sur de Brasil. Los datos fueron recolectados mediante entrevista semiestructurada con 12 enfermeros y analizados de acuerdo con el análisis de contenido temático. Resultados: surgieron tres categorías temáticas: el papel del enfermero en la búsqueda activa, el enfermero y las cuestiones burocráticas de la comisión intrahospitalaria de donación de órganos y tejidos y el enfermero y la familia del potencial donante de órganos. El enfermero se considera un eslabón entre el equipo de la comisión y los demás involucrados en el proceso de donación y extracción de órganos. Conclusión: el enfermero está presente en todas las etapas del proceso y tiene un papel importante en la búsqueda activa, en la gestión y la observación atenta del cuidado de enfermería al potencial donante. Descriptores: Enfermería; rol de la enfermera; trasplantes; obtención de tejidos y órganos.

\section{INTRODUÇÃo}

O Brasil desenvolve um programa de transplantes em processo de consolidação. Dados estatísticos apontam que a taxa de doador efetivo, obtida no primeiro trimestre de 2016, no Brasil, apresentou redução de $7,1 \%$ quando comparada ao ano de 2015 , ficando, ainda, $18,1 \%$ abaixo da previsão ${ }^{1}$.
A legislação brasileira relacionada à doação e captação de órgãos e transplantes é antiga e vem sendo alterada ao longo de sua história, no sentido de adequá-la e aperfeiçoá-la. Atualmente, a lei em vigor formaliza e institui as Comissões Intra-Hospitalares de Doação de Órgãos e Tecidos para Transplante (CIHDOTT)². 
As CIHDOTTs são compostas por equipes multiprofissionais que desempenham um papel importante na obtenção de órgãos, pois, estão alocadas dentro das unidades hospitalares, realizando a busca ativa por potenciais doadores, educação e conscientização social sobre doação de órgãos. Essas comissões são formadas por uma equipe multiprofissional do quadro de funcionários das instituições, destacando-se que somente o médico e o enfermeiro podem assumir o papel de coordenador ${ }^{2}$. Independente do papel de coordenador ou não das CIHDOTTs, a função do enfermeiro nestas comissões têm sido reconhecida e relacionada ao sucesso do transplante ${ }^{3}$. Isto deve-se ao fato de o enfermeiro ser reconhecido como um profissional que, através de seu conhecimento técnico e sua desenvolvida habilidade interpessoal, possibilita o aumento e a fluidez do processo de captação e doação de órgãos, o que repercute na quantidade 4 .

Em contrapartida, há de se considerar que embora essa seja uma área de atuação do enfermeiro, pouco tem sido discutido sobre esse tema. Estudos apontam que, apesar dos enfermeiros serem os profissionais mais próximos dos pacientes e atuarem como membros de CIHDOTTs, existem lacunas na educação formal sobre a doação de órgãos que precisam ser preenchidas ${ }^{5-7}$.

Diante desse contexto, há necessidade de abordar, tanto o processo formativo, como o âmbito da produção científica, sobre o papel do enfermeiro nesse processo, ampliando as bases teóricas para sustentação de uma atuação mais segura e eficaz. Nessa perspectiva, desenvolveu-se a seguinte questão de pesquisa: qual é o papel do enfermeiro atuante em CIHDOTT? Assim, o presente estudo teve como objetivo conhecer o papel do enfermeiro nessa comissão.

\section{REVISÃo DE LITERATURA}

A atuação do enfermeiro no processo de doação de órgãos e tecidos para transplante consiste em trabalhar os diversos componentes desse processo. Estudo brasileiro de 2016 evidenciou que fatores como medo, estresse, religião e conhecimento são os motivos que mais dificultam os enfermeiros quando confrontados com o processo de doação de órgãos. E o mesmo estudo considerou que o enfermeiro, por suas características profissionais, como a proximidade e conforto dado ao paciente e familiares, habilidades de comunicação, é parte importante no processo de doação de órgãos de sucesso ${ }^{8}$.

Vários estudos ao redor do mundo corroboram o exposto, anteriormente, ao fazerem menção à relevância do enfermeiro membro das CIHDOTT, como um profissional necessário e partícipe do processo de doação: na Polôniaa ${ }^{9}$, na Holanda ${ }^{10}$, na China $^{11}$, na Turquia ${ }^{12}$, no Irã ${ }^{13}$, na Austrália ${ }^{14}$, na Suécia ${ }^{15}$, nos Estados Unidos ${ }^{16}$ e no Brasil| ${ }^{3,8,17}$. Conforme diversos autores, o Brasil também reconhece a forte influência do enfermeiro no processo de doação de órgãos e ampara sua atuação ao citá-lo, juntamente com o médico, na legislação vigente, como sendo os únicos profissionais que podem ser coordenadores de CIHDOTT brasileiras 2,18,19. Ao finalizar esta seção, percebe-se que, apesar da importância do tema e o fato de o enfermeiro ser um elemento indispensável no processo de doação de órgãos, pouco se tem produzido sobre o seu papel nessa comissão.

\section{Metodologia}

Trata-se de uma pesquisa qualitativa, com caráter descritivo. Desenvolveu-se em cinco hospitais de uma Região Metropolitana do Sul do Brasil, que possuem CIHDOTTs registradas no Ministério da Saúde.

Os participantes foram enfermeiros atuantes em CIHDOTT. Para tanto, elencaram-se como critérios de inclusão: ser profissional enfermeiro e que atuasse em CIHDOTT há, no mínimo, 6 meses. Foram excluídos os profissionais em férias ou afastamento por qualquer motivo durante a coleta de dados. Ao total foram entrevistados 12 enfermeiros. Buscou-se a paridade no número de participantes entre os cenários pesquisados, levando em consideração o número de enfermeiros alocados na CIHDOTT. No cenário 1: dois participantes; cenário 2: três participantes; cenário 3: dois participantes. Cenário 4: um participante; e cenário 5: quatro participantes. O período de coleta ocorreu nos meses de maio e junho de 2014.

Para a coleta de dados, utilizou-se um formulário para a caracterização sociodemográfica, e um roteiro de entrevista semiestruturada com questões sobre o tema. O levantamento de dados teve início após autorização institucional e contato formal com os participantes, que se dispuseram e aceitaram conceder a entrevista, após a assinatura do Termo de Consentimento Livre e Esclarecido (TCLE).

As entrevistas foram audiogravadas e transcritas na íntegra. Os participantes foram identificandos por números cardinais sequenciais, conforme de realização da entrevista (E1...). O tratamento dos dados foi realizado com base na análise de conteúdo temática ${ }^{20}$. 0 estudo foi desenvolvido em consonância com a Resolução $n^{\circ}$ 466/2012 do Conselho Nacional de Saúde ${ }^{21}$. Dessa forma, obteve-se parecer emitido pelo Comitê de Ética em Pesquisa com Seres Humanos, sob o número 578.553.

\section{RESULTADOS}

Os participantes deste estudo possuíam idade entre 24 e 53 anos. A maioria dos entrevistados (91\%) era do sexo feminino. Os enfermeiros de CIHDOTT, em sua totalidade, possuem uma ou mais especializações - em Intensivismo (42\%), em Centro Cirúrgico (25\%), em Urgência e emergência (25\%). E ainda, entre os participantes, $17 \%$ são especializados em Doação e Transplante. Os resultados estão organizados nas seguintes categorias temáticas: o papel do enfermeiro na 
busca ativa; o enfermeiro e as questões burocráticas da CIHDOTT; e o enfermeiro e a família do potencial doador de órgão. Estas categorias são explanadas a seguir.

\section{O papel do enfermeiro na busca ativa}

Nesta categoria, os depoimentos evidenciaram que o enfermeiro está presente e é ativo na CIHDOTT, conforme os relatos que se seguem.

Nós somos o principal profissional do grupo, porque cuidamos da parte assistencial, da manutenção do potencial doador, da parte burocrática[...]. (E2)

[...] o enfermeiro membro da CIHDOTT, é a base, é o interlocutor com os demais profissionais. (E9)

Depreende-se dos depoimentos, que os profissionais reconhecem o seu papel na CIHDOTT. Este fato pode estar relacionado ao processo de atuação do profissional enfermeiro, particularmente relacionadas ao gerenciamento do cuidado e visão de conjunto, segundo os seguintes relatos:

wwPorque nós nos relacionamos melhor com os médicos e com a equipe. (E1)

Os relatos, a seguir, evidenciam que a forma como o enfermeiro atua - seu trabalho e o seu posicionamento perante a equipe - o que favorece na posição de elo entre os demais membros da CIHDOTT.

O enfermeiro tem o olhar diferenciado e isso sobressai também na CIHDOTT. Quanto à questão de trabalho em equipe, o enfermeiro [...] é o coordenador da equipe [...]. (E11)

Há alguns dias atrás, o médico que estava na emergência pediu para o [citou o nome do médico coordenador da CIHDOTT] chamar-me para eu ficar lá, por que ela [assistente social que estava de plantão] não iria mudar em nada e eu sabia manter o potencial doador [...]. (E1)

Outra função do profissional enfermeiro é a busca ativa por possíveis doadores de órgãos. Nesse caso, ao deparar-se com situações em que pacientes podem evoluir para o diagnóstico de morte encefálica, o enfermeiro da CIHDOTT atua de forma intensa, participando de todas as etapas do processo, conforme os depoimentos a seguir:

Desde a identificação do possível doador, fazemos busca ativa em todo o hospital. Olhamos os exames [...], se está recebendo sedação ou não. Chamamos o neurologista para avaliar. Acompanhamos a abertura do protocolo [...], desde o inicio da identificação do possível doador até a entrega do corpo para a família depois da captação[...]. (E4)

Acompanhando, por via telefônica ou no hospital, como está evoluindo aquele caso. Geralmente isso durante o horário comercial, acontece na busca ativa, já se identifica quais são esses pacientes. (E6)

\section{O enfermeiro e as questões burocráticas da CIHDOTT}

Esta categoria discorre sobre os aspectos burocráticos que envolvem o processo de captação e doação de órgãos e tecidos. Assim, entre as funções relatadas pelos participantes, estão as atividades burocráticas relacionadas aos registros, notificações, escalas e rotinas, sobre os dados dos protocolos e processos de doação de órgãos e tecidos.

Todos os relatórios mensais eu cuido, desde quantidade de transplantes que são realizados, quais, faço tabelas que vão para a central de transplantes [...]. (E1)

Fazemos toda a parte burocrática, que servirá para comunicar a central [refererindo-se a Central de transplantes] confere se está tendo preenchimento adequado, para a gente enviar a documentação. (E12)

\section{O enfermeiro e a família do potencial doador de órgão}

Nesta categoria, os participantes deste estudo relatam como acontece a abordagem do familiar no processo de doação e captação de órgãos e tecidos. Dessa forma, o enfermeiro durante este processo permite o contato com os familiares, pois, uma vez confirmado o diagnóstico de morte encefálica, a equipe precisa noticiar este fato à família. Nesse caso, destaca-se a importância da sensibilidade para conduzir todo o contato com os familiares, o que favorece a aproximação deles e a criação do vínculo, visando ao diálogo sobre a doação de órgãos do paciente em morte encefálica.

[...] tento priorizar o que é fundamental para captação, mas, muitas vezes, nos deparamos com situações que exigem outras coisas. Assim podemos perder o foco e, às vezes, os familiares estão desesperados e, conforme as palavras utilizadas, podemos perder um potencial doador, ou uma doação[...]. (E10)

A sensibilidade, relatada pelos participantes, muitas vezes, exige que os enfermeiros da CIHDOTT, sejam cautelosos e pacientes com os familiares. Para tanto, é preciso ter empatia com a família e não a pressionar, mesmo reconhecendo que o tempo é precioso para a perfusão e preservação da qualidade dos órgãos para transplante.

Se eles nunca ouviram falar sobre isso, se eles não esperavam aquilo naquele momento. Retire-se. Deixe que eles conversem para que cheguem num consenso. (E6)

Deixo-os livres, [referindo-se aos familiares] bem livres sobre a decisão e coloco a doação como uma oportunidade. (E11)

Assim, os resultados evidenciam a importância do enfermeiro como membro da CIHDOTT. O enfermeiro tem um papel de destaque nessa comissão, especialmente no que tange à coordenação e organização do processo, desde o estabelecimento do diagnóstico de morte encefálica e até a doação de órgãos propriamente dita, o que inclui ter a sensibilidade necessária para abordagem da família em momento tão delicado.

\section{DISCUSSÃO}

Os depoimentos relatam que o enfermeiro é considerado um elo entre a equipe da CIHDOTT. Isso está relacionado com a sua trajetória acadêmica e profissional, na qual ele encontra meios, subsídios e competência, que o tornam um gestor e/ou administrador. Assim, no papel de liderança, ele desempenha uma atribuição 
importante no processo de doação e transplante de órgãos nas organizações ${ }^{5}$.

Desse modo, o enfermeiro da CIHDOTT vem adquirindo novos espaços, conquistando as equipes assistentes, e, assim, consolida vínculos, dos quais emergem sentimentos de confiança e segurança entre os profissionais da saúde e os enfermeiros. Entretanto, ao considerar o grau de complexidade que envolve o processo de doação e captação, a equipe multiprofissional deve ser capaz de suprir as necessidades do potencial doador, dispondo de conhecimentos atualizados 22,23 .

O enfermeiro, ao demonstrar domínio e habilidade no desenvolvimento do seu trabalho, acaba assumindo uma posição de líder frente ao processo, tornando-se um elemento facilitador no processo de doação de órgãos e transplantes ${ }^{3,9-17}$. Ao considerar a complexidade que permeia todo o processo de doação e transplantes de órgãos, o enfermeiro não só entende, mas, se sensibiliza com as pessoas envolvidas. A sensibilidade demonstrada nos depoimentos expressa a essência do cuidado, que vai além do paciente em si. Assim, este profissional se preocupa e se relaciona com todos os envolvidos no processo de doação ${ }^{24}$, em especial, com a família ${ }^{10,12}$. Entende-se que o profissional enfermeiro compreende e respeita a autonomia das famílias, e por isso tende a tornar essa experiência positiva, tanto para a equipe multidisciplinar como para os familiares ${ }^{8,25}$.

Depreende-se, então, que atitudes vão além da técnica, fundamentam-se numa relação constante de troca com o outro, que perpassa pelo toque, pela comunicação, pelo cuidado físico e pelo respeito, constituindo assim uma relação humanizada ancorada nos preceitos éticos e legais s, $^{26}$. Nessa perspectiva, este profissional destaca-se na CIHDOTT, e se projeta na equipe multidisciplinar, por reunir habilidades e competências no desenvolvimento das mais variadas atividades relacionadas ao processo de doação e transplante de órgãos ${ }^{28}$. A busca ativa é reconhecida como a principal ação da CIHDOTT, pois, no desenvolvimento desta ação, é possível avaliar, diagnosticar, identificar, e, ainda, realizar cuidados durante o período da perfusão e preservação da qualidade dos órgãoes para transplante ${ }^{3,29}$.

\section{CONCLUSÃO}

A partir deste estudo evidencia-se que o enfermeiro tem papel fundamental no processo de doação de órgãos e tecidos para transplante e sua atuação envolve todos os processos desde a identificação, manutenção, doação, captação e transplante de órgãos. É referido, por seu conhecimento, habilidade interpessoal e sensibilidade para com todos os envolvidos, como um facilitador do processo de doação de órgãos, sendo um elemento importante para o aumento das taxas de doação de órgãos no Brasil.

Sua atuação é presente em todas as etapas do processo, mesmo antes da identificação do possível doador.
Desse modo, sua função na CIHDOTT está centrada na busca ativa, na gestão e observação atenta do cuidado de enfermagem ao potencial doador, além da postura profissional e sensibilidade que são características que permitem ao enfermeiro executar seu papel.

Como membro de CIHDOTT, o papel do enfermeiro estende-se também às questões burocráticas, notificações, construção de escalas e rotinas, procedimentos operacionais padrão, registros dos dados de protocolos, ações voltadas para a capacitação e a educação continuada de profissionais da saúde. O enfermeiro foi mencionado como um profissional indispensável entre a equipe assistencial, a família, e as equipes da central de transplantes, sendo o elo por onde esses componentes se inter-relacionam. Este estudo apresentou limitações em relação ao contingente reduzido de entrevistados e, ainda, por pesquisar esta questão em uma única região do país. Entretanto, o artigo reflete uma realidade local, contribuindo para o desenvolvimento de novos estudos com vistas ao aprimoramento do enfermeiro na CIHDOTT.

\section{REFERÊNCIAS}

1. Associação Brasileira de Transplante de Órgãos. [site da Internet]. Dados numéricos da doação de órgãos e transplantes realizados por estado e instituição no período (jan-mar 2016). 2016 [citado em 01 fev 2017]. Disponível em: http://www.abto. org.br/abtov03/Upload/file/RBT/2016/rbt1trim-2016-leit.pdf.

2. Ministério da Saúde (Br). Portaria GM/MS n².600/2009. Aprova o Regulamento Técnico do Sistema Nacional de Transplantes. Brasília (DF): 2009.

3. Mendes KDS, Roza BA, Barbosa SFF, Schirmer J, Galvão CM Transplante de órgãos e tecidos: responsabilidades do enfermeiro. Texto \& contexto enferm. (Online). [internet] 2012 [citado em 01 fev 2017]; 21(4):945-53. Disponível em: http://www.scielo.br/ pdf/tce/v21n4/27.pdf.

4. Freire ILS, Mendonça AEO, Bessa FM, Melo GSM, Costa IKF, Torres GV, et al. Compreensão da equipe de enfermagem sobre morte encefálica e a doação de órgãos. Enferm. glob. [internet] 2014 [citado em 04 jan 2017]; 36(8):70-8. Disponível em: http:// scielo.isciii.es/pdf/eg/v13n36/pt_administracion1.pdf.

5. Swain, S. The role of clinical nurse educators in organ procurement organizations. Prog. transplant. [internet] 2011 [cited 2017 Jan 04];21(4):284-7. Available from: http://www.ncbi.nlm. nih.gov/pubmed/22548988.

6. Hart JL, Konh R, Halpern S. Perceptions of organ donation after circulatory determination of death among critical care physicians and nurses: a national survey. Crit. care med. [internet] 2012 [cited 2017 Apr 04];40(9):2595-600.

7. Doria DL, Leite PMG, Brito FPG, Brito GMG, Resende GGS, Santos FLLSM. Conhecimento do enfermeiro no processo de doação de órgãos. Enferm. foco (Brasília). [internet] 2015 [citado em 30 mai 2017]; 6 (1/4): 31-5. Disponível em http://revista.portalcofen. gov.br/index.php/enfermagem/article/view/573.

8. Tolfo F, Camponogara S. O papel do enfermeiro frente ao processo de doação de órgãos: uma revisão integrativa. Evidentia (Granada). [internet] 2016 [citado em 16 abr 2017];13(54):10405-7. Disponível em: http://www.index-f.com/ evidentia/n54/sumario.php.

9. Czerwinskl J, Danek T, Trujnara M, Parulski A, Danielewcis R. System of donor hospital transplant coordinators maintained and financed by national transplant organization improves donation rates, but it is effective only in one half of hospitals. Transplant. proc. [internet] 2014 [cited $2017 \mathrm{Apr} 15$ ]; 46:(8):2501-4. Available from: https://www.journals.elsevier.com/transplantation-proceedings. 
10. Groot J, Vernooij-Dassen M, Vries A, Hoedemaekers C, Hoitsma $A$, Smeets $W$ et al. Intensive care staff, the donation request and relatives' satisfaction with the decision: a focus group study. BMC anesthesiol. (Online). [internet] 2014 [cited 2017 Apr 15]; 14(52):1471-2253. Available from: https://www.ncbi.nlm.nih. gov/pubmed/25057260.

11. Hu D, Huang $\mathrm{H}$. Knowledge, attitudes, and willingness toward organ donation among health professionals in China.

Transplantation. [internet] 2015 [cited 2017 Apr 15]; 99 (7):137985. Available from: https://www.ncbi.nlm.nih.gov/pubmed/26038874.

12. Kocaay AF, Celik SU, Eker T, Oksuz NE, Akyol C, Tuzuner, A. Brain death and organ donation: knowledge, awareness, and attitudes of medical, law, divinity, nursing, and communication students. Transplant. proc. [internet] 2015[cited 2017 Apr 15]; 47:(5):1244-8. Available from: https://www.ncbi.nlm.nih.gov/ pubmed/26093691.

13. Shabanzadeh AP, Sadr SS, Ghafari A, Nozari BH, Toushih M. Organ and tissue donation knowledge among intensive care unit nurses. Transplant. proc. [internet] 2009 [cited $2017 \mathrm{Apr}$ 15]; 41(5):148-82. Available from: http://www.transplantation-proceedings.org/article/S0041-1345(09)00293-0/abstract. 14. Marck CH, Weiland TJ, Neate SL, Hickey BB, Jelinek GA. Australian emergency doctors' and nurses' acceptance and knowledge regarding brain death: a national survey. Clin. transplant. [internet] 2012 [cited 2017 Apr 15];26(3):254-60. Available from: https:// www.ncbi.nlm.nih.gov/pubmed/22583165.

15. Forsberg A, Lennerling A, Fridh I, Rizell $M$, Lovén C, Flodén A. Attitudes towards organ donor advocacy among Swedish intensive care nurses. Nurs. crit. care. [internet] 2015 [cited 2017 Apr 15]; 20(3):126-33. Available from: https://www.ncbi.nlm.nih.gov/ pubmed/25611200.

16. Caillouet OC, Booker QG. Converting family advocates to level 1 recovery coordinators. Transplant. proc. [internet] 2008 [cited 2017 Apr 15]; 40 (4):1041-3. Available from: https://www.ncbi. nlm.nih.gov/pubmed/18555110.

17. Soares CB, Komura HLA, Peduzzi M, Sangaleti C, Yonekura T, Silva DRAD. Revisão integrativa: conceitos e métodos utilizados na enfermagem. Rev. Esc. Enferm. USP. [internet] 2014 [citado em 18 abr 2017]; 48(2):335-45. Disponível em: http:// www.scielo.br/scielo.php?script $=$ sci_arttext \&pid=S0080$-62342014000200335 \&$ Ing=en.

18. Conselho Federal de Enfermagem [internet]. Resolução Cofen-292/2004. Normatiza a atuação do enfermeiro na captação e transplante de órgãos e tecidos. 2004. [citado em 18 abr 2017]. Disponível em: www.cofen.gov.br/resoluo-cofen-2922004_4328.html. 19. Ministério da Saúde (Br). Portaria GM/MS n. 905/2000. Estabelece a obrigatoriedade da existência e efetivo funcionamento da comissão intra-hospitalar de transplantes. Brasília (DF): Gabinete Ministerial; 2000.
20. Minayo MCS. O desafio do conhecimento: pesquisa qualitativa em saúde. 14a ed. São Paulo: Hucitec; 2014.

21. Ministério da Saúde (Br). Conselho Nacional de Saúde. Resolução no. 466/12. Regulamenta pesquisas em seres humanos no Brasil. Ministério da Saúde. Brasília (DF): 2012.

22. Avila LI, Silveira RS, Lunardi VL, Machado GFF, Mancia JR, Silveira JT. Implicações da visibilidade da enfermagem no exercício profissional. Rev. gaúch. enferm. [internet] 2013 [citado em 04 jan 2017]; 34(3):102-9. Disponível em: http://www.scielo.br/scielo. php?script=sci_arttext\&pid=S1983-14472013000300013\&lng=en. 23. Pestana AL, Santos JLG, Erdmann RH, Silva EL, Erdmann AL. Pensamento lean e cuidado do paciente em morte encefálica no processo de doação de órgãos. Rev. Esc. Enferm. USP. [internet] 2013 [citado em 12 jan 2017] 47(1):258-64. Disponível em: http:// www.scielo.br/scielo.php?script=sci_arttext\&pid=S00806234201 3000100033\&lng=en\&nrm=iso.

24. Chernicharo IM, Freitas FDS, Ferreira MA. Humanização no cuidado de enfermagem nas concepções de profissionais de enfermagem. Esc. Anna Nery Rev. Enferm. [internet] 2011 [citado em 12 jan 2017]; 15(4):686-93. Disponível em: http://www.scielo. $\mathrm{br} / \mathrm{pdf} / \mathrm{ean} / \mathrm{v} 15 \mathrm{n} 4 / \mathrm{a} 05 \mathrm{v} 15 \mathrm{n} 4$.

25. Cappellaro J, Silveira RS, Lunardi VL, Corrêa LVO, Sanchez MLS, Saioron I. Comissão intra-hospitalar de doação de órgãos e tecidos para transplante: questões éticas. Rev Rene (Online). [internet] 2014 [citado em 14 jan 2017]; 15(6):949-56. Disponível em: http://www.revistarene.ufc.br/revista/index.php/revista/ article/viewFile/1813/pdf.

26. Silva TO, Silva ALF, Barbosa AC, Campos Júnior AP. Morte: percepção de enfermeiros que atuam na unidade de terapia intensiva do hospital municipal Milton Pessoal Morbeck.

Rev. interdisciplin. estud. exp. anim. hum. [internet] 2014 [citado em 20 mai 2017]; 1(11):102-6. Disponível em: http://revista. univar.edu.br/index.php/interdisciplinar/article/view/284.

27. Vieira MS, Nogueira LT. O processo de trabalho no contexto da doação de órgãos e tecidos. Rev. enferm. UERJ. [internet] 2016 [citado em 11 abr 2017]; 23(6):825-31. Disponível em: http:// www.e-publicacoes.uerj.br/index.php/enfermagemuerj/article/ view/11744/16200

28. Gresta MM, Moraes DT. A inserção do enfermeiro nas comissões intra-hospitalares de doação de órgãos e tecidos para transplante - CIHDOTT. Hospital das Clínicas, UFMG. Rev. med. Minas Gerais (Online). [internet] 2013 [citado em 01 abr 2017]; 23 supl 1:S1-S84. Disponível em http://docplayer.com.br/8899519-Rev-med-minas-gerais-2013-23-supl-1-s1-s84.html 29. Lima CSP, Batista ACO, Barbosa SFF. Percepções da equipe de enfermagem no cuidado ao paciente em morte encefálica. Rev. eletrônica enferm. [internet] 2013 [citado em 20 mai 2017]; 15(3):778-87. Disponível em: https://revistas.ufg.br/fen/article/ view/17497. 